There are two other circumstances in which attention to posture is most important.

The first is the condition of the patient after certain fits of epilepsy, the respiration being impeded by rattles in the throat. The posture should be much raised; but besides this, it should not be such that the saliva may fall into the fauces. The stupor and insensibility prevent the patient from swallowing. The saliva, therefore, if a just position be not adopted, accumulates and falls into the fauces, and a throat-rattle and dyspnœa, painful to witness, and dangerous to life, are the consequence. The posture of the patient should be such as to allow the saliva to flow out of the corner of the mouth. In one case such a change of posture relieved the patient imnediately.

The second case requiring extreme attention to the posture of the patient is that of Syncopal Epilepsy, or that form of epi lepsy in which there is ghastly pallor of the countenance and other signs of syncopal affection. The patient should be placed with the head low. If this be not done, the syncope may be speedily fatal, an event which actually occurred in an interesting case a few days only ago.

The patient was no other than Ann Ross, on whom Mr. Anderson had performed the operation of tracheotomy. Her fits had changed from those of the epilepsia laryngea to the abortive form. The reader may remember that the patient's age was thirty-six; that her case was hereditary, her father having been epileptic; and inveterate, her fits having recurred during twenty-four years; and that she herself was thin and pallid. She was seized with syncopal epilepsy; was laid on the bed and expected to recover as formerly; was left; and was at length found to have expired! A low position and proper attention might have saved the poor creature's life.

I need scarcely observe, that what I have said of epilepsy applies to many other diseases. It is the principle of position which I wish to enforce; a principle the importance of which I believe to be still greater and still more extensive in application than is generally imagined.

\section{FATAL HAMATURIA FROM PECULIAR GROWTHS IN THE BLADDER.}

BY DANIEL HOOPER, B.A., M.B. LoND., M.R.C.P., \&c.

THE following very interesting and instructive case of hæmaturia has lately occurred in my practice:-

James $\mathrm{E}-$, aged thirty-four, a railway porter, a remarkably robust and well-made man, of sanguine temperament, steady habits, and good general health, and who never was the subject of any serious disease or accident, became a patient of the Surrey Dispensary under my care, on the 17 th of November, 1852-four days before his death.

I ascertained that four months ago, without any premonitory illness or symptoms, he first observed blood in his urine. This being unattended with any pain or other symptoms, he continued his work for one month, the hæmaturia going on, and then feeling feeble and unwell, he applied for advice; and for the last three months has been under medical treatment. He told me, that during this period he had taken steel, lead, and turpentine without any effect; the hæmaturia having never once been checked from the first moment it was discovered. Once, about the end of September, he applied at the surgery of Guy's Hospital for relief from retention of urine; when a catheter was passed, which gave him intense pain, and relieved his bladder of an enormous quantity of bloody urine and coagula. After this, he said, the hæmaturia and failure of strength progressed rapidly. On November 17, at six P.M., I found him excessively bleached, complaining of headache, watchfulness, thirst, rapid prostration of strength, and tendency to syncope on any motion of the body. His tongue, and mucous membrane of the mouth, were almost white. Pulse 120, feeble, but jerking; skin dry, white, and feverish. He was passing from three to four pints of urine daily, of a very dark brown colour, with large, black, semimembranous, cystiform clots at the bottom of the vessel. One or two of these clots accompanied each emission of urine, and, in their transit through the urethra, occasioned great pain and sense of obstruction; although he always (except in the one instance mentioned) eventually got rid of them without instrumental aid. Their appearance was so unlike that of mere blood, that until Mr. Birkett had examined them microscopically, I was not convinced that they were such. His bowels acted daily, his appetite was not much amiss, and he was not conscious of any wasting of the body, which, to me, appeared fat and well-nourished. He had no pain anywhere, and every organ appeared healthy. I ordered him ten grains of Dover's powder, in two pills, at bed-time, and the following draught every four hours:-Gallic acid fifteen grains, diluted sulphuric acid fifteen minims, decoction of bark one ounce and a half. I also directed him to use a good diet, and to assuage his thirst allowed him cold spring water, with the addition of small quantities of alum and port-wine. After some hours he felt better; had slept, and was in good spirits. The same plan was continued, but the benefit was only temporary; and after trying matico, \&c., I found him much worse on the 21 st. Pulse 100, very feeble, and less jerking; a sense of rapid sinking; slow, sighing respiration, cold skin, \&c.; and death by asthenia and syncope occurred at four A.M., on the 22 nd.

Post-mortem Examination at two P.M., in the presence of Drs. Gull and Wilks.--After turning aside the intestines, and removing an enormous quantity of fat, I dissected out and removed the kidneys, ureters, and bladder entire. The kidneys were large and very pale, but otherwise healthy, and weighed about seven ounces each. The right ureter was sufficiently dilated to admit the little finger; it led back wards to a dilated renal pelvis, and forwards to an opening in the bladder, so small as not to admit the point of a small blow-pipe. At this part of the bladder, on its internal surface, was a peculiar tufted growth, about the diameter of a sixpence, and oneeighth of an inch in depth or thickness, and in its vicinity were two or three much smaller and more vascular-looking tufts, but possessing the same general characters as the larger one. The bladder contained about three ounces of black coagula; its capacity was normal; its coats healthy; the muscular striæ, of course, very distinct; and the entire organ unusually pale. All the other organs were remarkably healthy, and not a trace of the disease found in the bladder could be found elsewhere. The heart contained a few dark coagula adhering to its auriculo-ventricular openings, and $I$ need scarcely say that the whole body and its contents were almost bloodless. It was very evident that the disease was strictly local, and limited to these growths in the bladder; that these had effectually drained the body of all its blood, and so killed an unusually powerful and otherwise healthy man. It is, therefore, of the highest importance to ascertain their origin, nature, and treatment. Now, what should give rise to them in such a man, I leave others to guess. Their structure is peculiar. When shaken in cold water, they spread out into a dense arborescent form, so that one could not say what bulk they might have occupied, when distended with blood, during life. Under the microscope, they appear to consist of most beautiful arborescent tufts, which, on close examination, seem to be made up of immense numbers of capillaries, covered with columnar, narrowly-elliptical, epithelial cells, with large nuclei. Lastly, as treatment and cure are the ends of all our knowledge, it would be a great and a good thing to be able to recognise this disease during life, and so to treat it that we might enable the patient to live, even if we could not get rid of the structure; and this much I believe we can do, (prevention with our present ignorance of the cause is of course impossible.) Connecting, then, this case with two others which occurred to Dr. Gull, of Guy's Hospital, I am of opinion that when we find continued hæmaturia in a person in all other respects healthy and well, without any history or symptom of any kind to unravel the case, we may pronounce it to be one of this peculiar disease of the bladder, and treat it as such; and $I$ would merely suggest, that in addition to some such treatment as that adopted in this case, the bladder should be injected with some powerful astringent, and the patient so kept alive.

I trust these remarks may lead myself and others to be on the look-out for the disease, and enable us to discover a cure, or at least some better treatment.

I hope, on some future occasion, to be prepared to describe more minutely the characteristics of these growths, which, as far as I know, have not yet received a name.

Wellington-street, London-bridge, Nov, 1852.

\section{A THERMOMETER FOR THE HUMAN BODY. \\ By J. SPURGIN, M.D. Cantab., \&c.}

$I_{T}$ is well known that there are variations of temperature in different parts of the body, and that these variations are frequently an important help to diagnosis in disease; but this knowledge is derived more from our sensations than by means of any suitable application of the thermometer. It is evident, however, that our sensations are quite inadequate to furnish an accurate test of temperature. To supply a want therefore 
in this respect, $I$ have constructed an instrument by means of which the medical practitioner can determine and record the relative degrees of heat of every part of the body in health or disease. As yet, the instrument, I believe, admits of further improvement, in regard more especially to quickness and delicacy of action; but already I have had very satisfactory proofs of its utility, by employing it in the several cases which I shall presently submit to the notice of the reader.

This instrument can, with the aid of the accompanying dia-

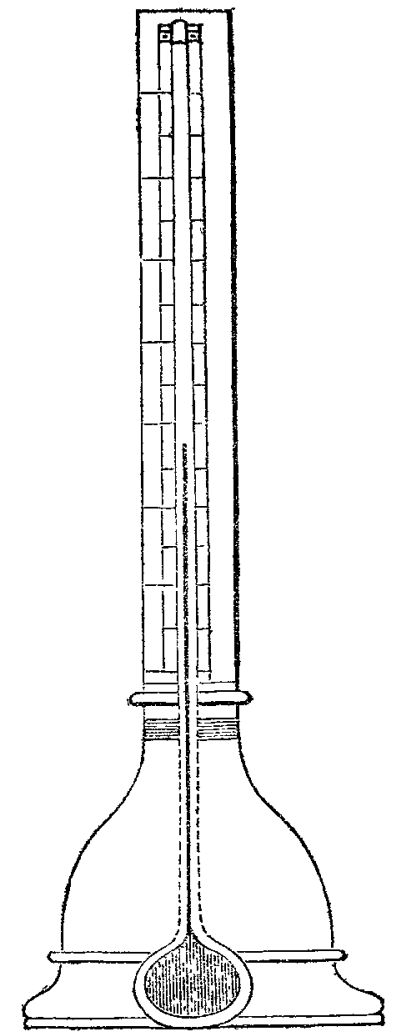

gram, be easily understood. It consists of a common thermometer, having its bulb and the lower part of its shaft suspended or fixed in a hollow cone of wood, so that the bulb descends nearly to the level of the lower rim of the cone; the portion of the shaft which rises out of the cone is affixed to a graduated ivory index, and the elevation of the mercury or spirit can be very readily and accurately ascertained. The shape of the bulb may be either spherical, or oval, or elongated, and bent at a right angle with the shaft; and as, in its application, it is placed in the centre of the hollow cone, it receives the heat which emanates from the point of examination both directly and by reflection from the internal surface of the cone; the rise of the mercury or spirit is consequently quicker than it could be in any common thermometer.

The cases to which I have alluded are as follow:-

CASE 1.-Miss W-, aged twenty-two, was Jabouring under continued fever, with symptoms of general depression, which caused great apprehension of a typhoid state supervening. I noticed the heat of several parts of the body, which varied in amount considerably, but about the occiput it was greater by three degrees at least than anywhere else. I concluded that the cerebellum was much oppressed, and its vessels turgid with blood, and that this condition was the cause of the alarm ing depression.

I relied on the test afforded me by the thermoscope, and ordered eight leeches to be applied around the occiput. The effect was very satisfactory, for not only did the heat of that part of the head quickly subside, but the depression of the heart and arteries disappeared, and the case proceeded with comparative ease, and with no further difficulty or apprehension to recovery.

I have no hesitation in saying, that had the cerebellum been overlooked, and suffered to remain in a state of vascular congestion, the case would have been much more formidable to manage throughout, more especially as there were, in addition to the depression of the heart and arteries, confusion of thought and other signs of cerebral disturbance setting in.

CASE 2.-A lady, aged twenty-eight, came from the country to consult me respecting a tumour in the left breast. It caused her serious alarm, for it had gradually increased in size, and resisted the treatment which her medical friend in the country had advised. Her general health was suffering, in consequence of the constant alarm she was enduring. The tumour was about the size of a large horse-chestnut; hard and painful when pressed; the nipple was retracted. I was much struck by the temperature of the affected breast exceeding that of the sound one, and I requested my patient to ascertain for herself the relative amount of heat in each breast. She soon reported that the affected breast was nearly four degrees lotter than the other, and that she had not the slightest doubt about it. I therefore prescribed eight leeches, and afterwards the lead lotion, and to have then repeated, four at a time twice a week; the patient took also effervescing saline medicines, with the sesquicarbonate of ammonia, and mild aperient pills every night.

The heat of the breast was reduced, the hardness and tenderness of the tumour were lessened, and her general health at length fully restored. From the great increase of heat of the affected breast, as compared with the sound one, and, indeed, with the rest of the body, I considered the tumour to be in a state of inflammation, and therefore requiring local relief, even in the absence of every other positive indication of inflammation. It is this increase of temperature in diseased parts which should be carefully noticed by the practitioner, with a view to reduce it to the natural equilibrium as quickly as possible; in so doing, not only may the extension of diseased action be lessened, but the disease itself removed. In this way, the thermoscope may be rendered a valuable aid in guiding us to a correct, as well as to a decided course of action, in the treatment of diseases, wherever they may be seated; and it will also assist in determining the nature of the disease, as to whether it be inflammatory, congestive, nervous, or otherwise.

CASE 3.-An elderly lady was suffering severely from pain in her loins, which she thought to be merely a rheumatic affection, On examination, I found she had been the subject of valvular disease of the heart for some time, and was much emaciated; but her urgent distress, for which I was consulted, arose from pain in her back. I applied the thermoscope over the region of each kidney, which indicated an increase of temperature of the right, as compared with the left, of full three degrees. An application of hot poppy fomentations to the seat of the pain, with saline medicines, and a few drops of laudanum, soon relieved her.

In two cases of astlima, I used the thermoscope conjointly with the stethoscope; and by reason of the increase of temperature of the affected parts of the lungs, as contrasted with the sound parts of them, I had recourse to leeches and counter-irritants, and purgation by a continued administration of rhubarb and sulphate of potass, with most decided benefit. Touching this latter medicine, according to my experience of the many methods of treatment of asthma in its common acceptation, I can assert that its efficacy in removing phlegm, relieving the dyspnca, and restoring the general health, surpasses them all.

In conclusion, I would recommend the thermoscope to the trial of the surgeon in his examination both of tumours and of diseased joints; and I shall be happy to communicate my further observations in regard to the use of this simple instru. ment from time to time, as well as to learn from my professional brethren the results of their trials of it, in the event of its being thought worthy of patient and careful employment in the investigation of diseased action.

Guildford-street, Russell-square, 1852 .

N.B.-The instrument may be procured at Mr. Biggs's, St. Thomas's-street, Southwark; at Mr. Weedon's, Hart-street, Bloomsbury; or ordered at any other surgical instrument makers.

\section{OBSERVATIONS ON THE IMPULSE OF THE HEART.}

By ROBERT CARTWRIGHT, Esq., Surgeon.

I HAFE been informed that some eminent physicians set but little value on vivisections; they feel perfectly satisfied that pathology alone indisputably proves the truth of the systolic theory of the heart's impulse. It cannot be denied that certain forms of cardiac disease at certain stages are diagnosed with considerable accuracy; this, however, is not at all surprising, since all the hospitals of Europe, especially during the last thirty years, have turned their attention earnestly to that point; and of course similar diseased appearances will accompany similar false sounds or bruits; but I have heard several able hospital physicians acknowledge the difficulty of the diagnosis, and it is universally understood that errors are 